\title{
Actualité de la recherche sur les mobiliers non céramiques de l'Antiquité et du haut Moyen Âge
}

Jean Soulat

\section{OpenEdition}

\section{Journals}

Édition électronique

URL : http://journals.openedition.org/rao/3176

DOI : $10.4000 /$ rao. 3176

ISBN : 978-2-7535-5014-8

ISSN : $1775-3732$

\section{Éditeur}

Presses universitaires de Rennes

\section{Édition imprimée}

Date de publication : 31 décembre 2015

ISBN : 978-2-7535-5012-4

ISSN : 0767-709X

Référence électronique

Jean Soulat, « Actualité de la recherche sur les mobiliers non céramiques de l'Antiquité et du haut Moyen Âge", Revue archéologique de l'Ouest [En ligne], 32 | 2015, mis en ligne le 28 avril 2016, consulté le 02 mars 2021. URL : http://journals.openedition.org/rao/3176 ; DOI : https://doi.org/10.4000/rao 3176 
Raux S., Bertrand I. et Feugère M. (dir.), 2015 - Actualité de la recherche sur les mobiliers non céramiques de l'Antiquité et du haut Moyen Âge, Actes de la table ronde européenne Instrumentum, Lyon (F. Rhône), 18-20 octobre 2012, Monographie Instrumentum 51, éditions Monique Mergoil, Montagnac, éditions Association des Publications Chauvinoises, Chauvigny, 2015, 716 p. (ISBN 978-2-35518-047-7).

Il y a près de 20 ans, le groupe de travail européen sur l'étude du petit mobilier archéologique antique Instrumentum voyait le jour et insufflait un nouvel élan sur la recherche archéologique avec la publication d'une collection de monographies depuis 1994 et la parution biannuelle d'un bulletin depuis 1997. En s'étendant aux périodes médiévale et moderne à partir de 2012, le groupe de travail a souhaité élargir son champ d'action et compter sur l'intégration de nouveaux membres. Malheureusement, l'étude de ces périodes reste largement sous représentée en comparaison aux périodes protohistorique et antique, autant dans les monographies que dans les bulletins.

La table ronde européenne Instrumentum intitulée "Actualité de la recherche sur les mobiliers non céramiques de l'Antiquité et du haut Moyen Âge " est le premier colloque qui affiche cette ouverture avec la représentation du début de la période médiévale. Se déroulant du 18 au 20 octobre 2012 aux Archives municipales de Lyon et au Musée gallo-romain de Lyon-Fourvière, les actes de la conférence sont publiés en 2015 dans la collection Monographies Instrumentum et constituent son $51^{\mathrm{e}}$ tome aux éditions monique mergoil de Montagnac, éditions Association des Publications Chauvinoises de Chauvigny. Ils constituent un volume conséquent de 716 pages.

Au total, ce sont donc 35 articles qui ont été réunis correspondant à 20 communications et 15 posters présentés lors de la table ronde. Ils se rassemblent autour de six thématiques. Le thème 1 "Aspects méthodologiques, apports des études de l'instrumentum à la compréhension d'un site " avec sept articles (p. 7-153), le thème 2 "Mobiliers de sites d'habitat " avec cinq articles (p. 155-242), le thème 3 "Mobiliers des sites funéraires et cultuels " avec sept articles (p. 243-374), le thème 4 «Productions artisanales et objets destinés à l'immobilier » avec sept articles (p. 375552), le thème 5 "Faciès instrumentum de Lugdunum " avec cinq articles (p. 553-650) et enfin le thème 6 "Variae " avec quatre articles (p. 651-716). À travers ces différents thèmes, on retrouve les types de site les plus couramment rencontrés pour les périodes évoquées : habitats, nécropoles, édifices de culte et sites de production. On peut cependant évoquer l'absence des sites à vocation commerciale comme les ports ou encore les épaves de navire.

Concernant les articles et posters, on distingue deux catégories de contribution : les études de cas de sites, 17 au total dont 11 issues de fouilles préventives et 6 de fouilles programmées, et les synthèses, 18 au total, qui concernent autant du mobilier que des sites livrant du matériel. La répartition est donc très équitable. À propos du cadre géographique des communications proposées, on compte de nombreuses localités évoquées dans l'ouvrage. 12 départements français sont représentés de l'Aisne au Gard et de la Loire-Atlantique à la Drôme. On ne peut cependant que regretter l'absence des régions du nord, de l'est et du sud-ouest de la France. Par ailleurs, cinq articles concernent des régions étrangères d'Italie et de Bulgarie.

Outre les types d'article, il faut évoquer parmi les 716 pages du volume, un nombre impressionnant de figures associant des planches de mobilier, type d'illustration auquel on s'attend dans un ouvrage consacré aux objets, mais également tout une série de cartes, de plans, de graphiques et de tableaux d'inventaire. Sur ces derniers, on ne peut que déplorer la présence d'une trentaine de pages, qui alourdit sensiblement le volume déjà conséquent. En effet, ces pages souvent hermétiques, car reproduites dans un format compressé, livrent des inventaires en annexe qui ne devraient pas apparaître dans un article, et qui pour ma part, sont normalement réservés aux rapports de fouille en particulier dans le cas de l'article sur les figurines en terre cuite (5 pages) ou de celui sur l'artisanat de l'os à Reims (7 pages). Dans ces deux exemples, il aurait fallu trouver une solution plus synthétique pour illustrer le comptage.

Parmi les nombreuses contributions, il faut mentionner quelques articles qui s'intéressent aux matériaux de construction antique propre à l'habitat et à leur fabrication : les diverses utilisations du marbre, les canalisations en bois et les tuiles en écaille. Thème en vogue depuis ces dernières années, ces trois articles de synthèse permettent d'agrémenter nos connaissances en la matière. La thèse de Christophe Loiseau sur le métal dans l'architecture publique de l'ouest de la Gaule Lyonnaise ( $\mathrm{I}^{\mathrm{er}}-\mathrm{III}{ }^{\mathrm{e}}$ siècles après J.-C.) en cours de publication viendra également compléter ces données sur un autre aspect.

Pour conclure, il faut relever la qualité d'impression de l'ouvrage, enrichit de très nombreuses figures en couleur, qui apportent une clarté à la lecture et à la mise en valeur des artefacts étudiés. Les planches typologiques d'objets, parfois très détaillées, livrent des corpus inédits qui témoignent d'une publication de référence en particulier le corpus provenant du site de la Caserne Niel de Toulouse. La quantité d'articles et de posters publiés sont la conséquence 
du développement de cette spécialité en archéologie préventive depuis plusieurs années. Allant dans ce sens, il faut saluer la diversité des intervenants associant des spécialistes expérimentés à de nouveaux acteurs de la discipline comme des étudiants présentant leurs travaux. Cette diversité s'exprime également par la variété des organismes représentés au colloque (ministère de la Culture, Inrap, collectivités territoriales et entreprises privées) qui traduit le nouveau visage de l'archéologie en France. Ces actes du colloque de Lyon livrent ainsi un volume fondamental pour la recherche de petit mobilier, mobilier non céramique ou instrumentum comme on l'appelle pour les périodes protohistorique et antique. Le titre du colloque "Actualité de la recherche sur les mobiliers non céramiques de l'Antiquité et du haut Moyen Âge " a donc été conservé pour sa publication. Très ambitieux, il tient donc toutes ses promesses compte tenu des productions proposées. Néanmoins, on ne peut que regretter la faible représentation des articles propre au haut Moyen Âge, seulement trois sur 35, constat qui montre que les efforts à fournir pour réunir les spécialistes des différentes périodes sont encore vains.

Jean SOULAT (Laboratoire LandArc - Craham UMR 6273)

Treffort C., Brudy P. (dir.), 2013 - Monastères entre Loire et Charente, Rennes, PUR, 320 p. + cahier central de XXXII Pl. couleur h. t.

Piloté par Cécile Treffort et Pascale Brudy, avec la collaboration d'Anne Autissier, cet ouvrage de 320 pages est issu d'un colloque intitulé Archéologie monastique en pays charentais... qui s'est tenu à Saintes et Saint-Amantde-Boixe ( $1^{\text {er }}-3$ avril 2005) et de travaux réalisés dans le cadre d'un projet collectif de recherche (PCR) mené de 2001 à 2008 sur les Conditions d'implantation des monastères dans les pays charentais au Moyen Âge... Si le titre de l'ouvrage manifeste la volonté d'étendre le propos jusqu'à la Loire, force est de constater que les études de sites localisés en dehors des pays charentais (actuels départements de Charente et de Charente-Maritime) sont peu nombreuses (deux sites en Vendée, un en Maine-et-Loire...). L'essentiel de la publication porte en effet sur un espace géographique et culturel présenté comme cohérent réunissant le littoral atlantique et le fleuve Charente.

L'ouvrage est introduit par Cécile Treffort dans un chapitre (p. 7-9) restituant l'histoire de cette entreprise collective et interdisciplinaire ayant réuni une vingtaine de chercheurs d'origines institutionnelles diverses pendant près d'une décennie. Le programme de recherche a également donné lieu à une exposition itinérante intitulée $A \grave{A}$ la table des moines charentais, publiée en 2005. L'ambition de ces travaux était de réunir un ensemble de données disparates et parfois inédites dans un ouvrage alternant approches synthétiques et études monographiques. Ce dernier est organisé en cinq parties.

La première partie, intitulée "Histoires de moines" (p. 15-36), s'ouvre par une contribution de Cécile Treffort, qui dresse un bilan historiographique de la vie monastique en pays charentais $\mathrm{du} \mathrm{V}^{\mathrm{e}}$ au XII ${ }^{\mathrm{e}}$ siècle. Elle brosse un tableau contrasté de la documentation disponible et des principaux courants ayant ponctué l'histoire monastique régionale, depuis l'éclosion des établissements religieux suburbains à la fin de l'Antiquité jusqu'aux monastères créés à fin du XI et au XII ${ }^{\mathrm{e}}$ siècles avant l'installation, au XIII ${ }^{\mathrm{e}}$ siècle, des ordres mendiants en milieu urbain.

Dans une seconde contribution, consacrée au prieuré Sainte-Sonne de Chadenac en Charente-Maritime, Luc Bourgeois, Bernard Farago-Szekeres et Brigitte Véquaud confrontent la littérature épique médiévale et les actes de la pratique aux données archéologiques. La fouille a notamment montré que l'établissement religieux est installé à l'emplacement d'une nécropole mérovingienne et d'une église ou chapelle funéraire remontant au début du vi siècle. Outre les vestiges immobiliers, se sont aussi d'autres aspects de la vie matérielle, et particulièrement la céramique, qui sont ici abordés.

La deuxième partie de l'ouvrage, subdivisée en cinq chapitres, traite des "Logiques d'implantation » (p. 37-90) des communautés religieuses en pays charentais.

Les deux premiers correspondent à des approches territoriales. La contribution de Sylvie Dinet Refaldo porte sur les prieurés charentais des abbayes poitevines aux $\mathrm{x}^{\mathrm{e}}$ et $\mathrm{XI}^{\mathrm{e}}$ siècles, qui représentent, à eux seuls, près d'un dixième des installations répertoriées en pays charentais. Ce phénomène s'explique par une combinaison de facteurs géographique, politique et économique. Les abbayes poitevines qui s'implantent en Charente sont aussi les plus prestigieuses et correspondent à celles où la présence des ducs d'Aquitaine est la plus marquée. La plupart de ces prieurés sont logiquement installés au nord du fleuve de la Charente, au sud du diocèse de Poitiers. Ce sont les abords de Charroux et de Nanteuil-en-Vallée, les axes de la Charente et de ses 